\title{
DISEÑO DEL ESCENARIO MÁS PROBABLE DE LA OSDE VIAJES CUBA AL AÑO 2025.
}

\section{DESIGN OF THE MOST PROBABLE SCENARIO FOR THE OSDE VIAJES CUBA IN 2025.}

Yoan Hernández Flores, Lcdo. Licenciado en Turismo (Cuba). Docente adiestrado de la Facultad de Turismo de la Universidad de La Habana, Cuba. yoan961122@gmail.com Maité Rodríguez González, MSc. Máster en gestión turística (Cuba). Docente auxiliar de la Facultad de Turismo de la Universidad de La Habana, Cuba. mrodriguez@ftur.uh.cu

Dr. C. Héctor Ayala Castro Doctor en Ciencias Económicas (Cuba). Profesor Titular de la Facultad de Turismo de la Universidad de La Habana, Cuba. hector.ayala@ftur.uh.cu

\section{ARTÍCULO DE INVESTIGACIÓN}

Recibido: 10 de junio de 2020.

Aceptado: 23 de junio de 2020.

\section{RESUMEN}

Los ejercicios de prospectiva estratégica en las empresas son de vital importancia para lograr los objetivos planteados a largo plazo, así como para la toma de decisiones estratégicas. En tal sentido, la construcción de escenarios permite exponer un conjunto de alternativas respecto al futuro de las organizaciones. Es por ello que, la presente investigación, se realizó con el propósito de establecer el escenario más probable, para el despliegue de la planeación prospectiva estratégica de la Organización Superior de Dirección Empresarial Viajes Cuba al año 2025. Se utilizó como base para los procedimientos a seguir la metodología propuesta por Godet y Durance (2011), la cual consta de tres fases para la construcción de escenarios, apoyándose además en los softwares desarrollados para los estudios prospectivos. Se determinó que, actualmente, la planeación estratégica de la entidad carece de una correcta formulación de algunos de sus elementos claves, incidiendo de forma negativa en el proceso de toma de decisiones. A partir del análisis inicial, se determinaron un total de 10 variables claves y 9 actores, 
identificándose 16 escenarios a partir de cuatro hipótesis diseñadas. Como resultado final se diseñaron los posibles escenarios y, se describe el más probable al año 2025.

Palabras claves: Prospectiva estratégica, construcción de escenarios, Organización Superior de Dirección Empresarial Viajes Cuba, toma de decisiones.

\section{ABSTRACT}

The strategic prospective exercises in companies are of vital importance to achieve the objectives set in the long term, as well as for strategic decision making. In this sense, the construction of scenarios allows to expose a set of alternatives about the future of organizations. That said, the present research, was carried out with the purpose of establishing the most probable scenario, for the deployment of the strategic prospective planning of the Organización Superior de Dirección Empresarial Viajes Cuba to the year 2025. It was used as the basis for the procedures to follow the methodology proposed by Godet and Durance (2011), which consists of three phases for the construction of scenarios, also relying on the software developed for prospective studies. It was determined that, actually, the strategic planning of the entity lacks a correct formulation of some of its key elements, negatively affecting the decision-making process. From the initial analysis, a total of 10 key variables and 9 actors were determined, identifying 16 scenarios from four designed hypotheses. As a final result, the possible scenarios were designed and the most probable one, in 2025, is described.

Keywords: Strategic prospective; scenario construction, Organización Superior de Dirección Empresarial Viajes Cuba, decision making.

\section{INTRODUCCIÓN}

Las empresas en la actualidad tienen el reto de estudiar el futuro por la complejidad del contexto decisional, caracterizado por la incertidumbre, inestabilidad, inexactitud de la información y alto nivel de conflicto; así como por la necesidad de contar con pronósticos expertos sobre el futuro, para tomar buenas decisiones estratégicas.

Predecir el futuro o construirlo de acuerdo a unas perspectivas no es una tarea sencilla. Los diferentes métodos como: los pronósticos cualitativos y cuantitativos, estudios prospectivos, la simulación, modelos causales, la futurología, entre otros, proporcionan los indicios de lo que podría deparar el día de mañana con el objetivo de reducir la incertidumbre. Por ello, prever el futuro se convierte en un aspecto clave para establecer planes estratégicos, anticipándose a posibles obstáculos o para aprovechar las oportunidades venideras (Vergara, Fontalvo y Maza, 2010). 
Desde inicios del siglo XXI, los estudios sobre el futuro han proliferado por todo el mundo gracias a la creación de numerosos organismos públicos y semipúblicos encargados de realizar ejercicios de previsión y prospectiva. Organismos internacionales como la Organización de las Naciones Unidas (ONU) y la Organización para la Cooperación y el Desarrollo Económico (OCDE) realizan con frecuencia ejercicios de prospectivas.

Actualmente, la prospectiva bien ejercida en las entidades del sector del turismo y específicamente en las agencias de viajes (AA.VV.), se reconoce como un proceso sistemático, participativo, de construcción de una visión a largo plazo para la toma de decisiones en la actualidad y para la movilización de acciones conjuntas (Dueñas, Medina, Ramírez, Camacho y Sobenis, 2019). La construcción de escenarios "permite exponer un conjunto de alternativas respecto al futuro y pone a discusión las consecuencias de tomar o no determinadas decisiones" (Firmenich, citado en Dueñas, Medina, Ramírez, Camacho y Sobenis, 2019).

Específicamente, en Cuba se comenzaron a realizar estos estudios durante la última década del siglo XX (desde 1989 hasta 2000), a partir del llamado "período especial", donde se implementaron estrategias mediante las cuales se ha desarrollado la planificación o planeación estratégica en los diferentes sectores (Calero y Fernández, 2007). En los últimos años, han cobrado mayor auge estos estudios, debido a la necesidad de cumplir con los Objetivos de Desarrollo Sostenible trazados por la ONU para el año 2030.

Hoy en día, los documentos del $7 \mathrm{mo}$. Congreso del Partido, aprobados por el III Pleno del Comité Central del Partido Comunista de Cuba y respaldados por la Asamblea Nacional del Poder Popular en el año 2017: Conceptualización del Modelo Económico y Social Cubano de Desarrollo Socialista; Bases del Plan Nacional de Desarrollo Económico y Social hasta el 2030: Visión de la Nación, Ejes y Sectores Estratégicos; Lineamientos de la Política Económica y Social del Partido y la Revolución para el período 2016-2021, marcan el rumbo del proceso revolucionario cubano, del Partido y la sociedad hacia el futuro.

Dentro de las acciones acometidas y como parte del proceso de perfeccionamiento funcional, estructural y composicional realizado por el país, se aprobó la constitución de Organizaciones Superiores de Dirección Empresarial (OSDE), lo que conllevó a la modificación de sus estructuras y a potenciar las funciones de la oficina central, cuya actividad principal es la de regulación y control (Hernández, González y Despaigne, 2018).

A través del Decreto 335/17, se le otorgan a las OSDE, funciones bien definidas para lograr que todas las empresas que se integren a ella se fortalezcan, ganen en eficiencia y competitividad. Tienen personalidad jurídica y patrimonio propio, financian sus gastos con los 
aportes de las empresas que la componen y su gestión tributa al beneficio de estas (Hernández, 2020).

Dentro de las nuevas estructuras, en el Ministerio del Turismo (MINTUR) se encuentra la OSDE Viajes Cuba, creada el 30 de diciembre del 2014, por el Ministro de Economía y Planificación, Marino Murillo Jorge e integrada por las AA.VV.: Havanatur S.A, Cubatur S.A, Cubanacán S.A y Ecotur S.A.

En el año 2016 en la OSDE Viajes Cuba, se realizó un estudio de planeación estratégica (2017-2022) donde se definieron aspectos básicos para su funcionamiento el de las agencias que ella agrupa.

A pesar de que la OSDE Viajes Cuba cuenta con aspectos ya definidos como la misión, visión, objeto social y algunos objetivos y planes trazados por las diferentes áreas de trabajo, en el año 2018 , respecto al 2017, todas las empresas de la OSDE incumplieron los principales indicadores directivos al no alcanzar las ventas brutas planificadas y las exportaciones de servicios.

Existen, además decrecimientos en indicadores como el nivel de satisfacción de los clientes. Según los informes comerciales de la entidad, durante el primer cuatrimestre del 2019, las quejas y reclamaciones ascendieron a 817, ocasionando gastos de aproximadamente 37946.82 CUC. Estas quejas son originadas, fundamentalmente, por el incumplimiento de los programas y la falta de coordinación entre las diferentes áreas de las agencias para el desarrollo de los servicios.

Incide además que, la definición de escenarios como fundamento del diseño de acciones estratégicas en el entorno de la OSDE, haya sido débilmente ejercitado, a pesar de los argumentos en torno a su importancia y pertinencia. Mientras que la multiplicidad de mercados, segmentos, líneas de productos, la profundidad de las mismas, la diferenciación entre productos y servicios bajo las que operan las AA.VV., exige por otra parte, la necesaria identificación, descripción y valoración de las variables, actores e hipótesis que determinen sus escenarios, como fundamento científico de la planeación estratégica.

Ante esta problemática, y en aras de sustentar una planificación estratégica que permita elevar los niveles de competitividad a largo plazo, de las agencias que integran la OSDE Viajes Cuba, se define como objetivo general: Establecer el escenario más probable, para el despliegue de la planeación prospectiva estratégica al 2025.

\section{REVISIÓN TEÓRICA}

Según Hernández (2020), el término planificación ha sido abordado por autores como Ansoff (1965), Chiavenato (1999) y González (2004), los cuales concuerdan que planificar es el 
establecimiento de objetivos o metas, y la elección de los medios más convenientes para alcanzarlos (planes y programas).

La planificación, en el ámbito empresarial, es previa a las otras funciones de dirección; pues es imposible organizar, gestionar y controlar con eficacia sin unos planes adecuados (Gorostegui, citado en Clemade 2010).

Elementos fundamentales en este proceso de planificación, son la selección de la información, el desarrollo de acciones con el fin de lograr el objetivo que se persigue, lo que implica conocerlo, evaluar la situación, considerar diferentes acciones que puedan realizarse y escoger la mejor alternativa.

D'Alessio plantea que Alfred Chandler, Chris Argyris, y Kenneth Andrews de la Harvard Business School, los primeros en tratar sobre estrategia empresarial, definen la planificación estratégica como el elemento que determina las metas y objetivos básicos de largo plazo de una organización, y la adopción de cursos de acción, acompañada de la asignación de recursos necesarios para lograr dichas metas (González et al, 2019).

Varios autores, han realizado estudios sobre la evolución de la planificación en las empresas. Baena (2015) plantea que, con la evolución de los estudios en administración se pueden definir seis tipos de planeación: clásica, reactiva, inercial o proyectiva, de contingencia, estratégica y prospectiva estratégica. De igual forma enuncia que, el último tipo de planeación surge, debido a que es imposible realizar una planificación a largo plazo sin estudiar los escenarios futuros, de ahí que esté muy vinculada a la prospectiva.

Los estudios prospectivos comienzan a realizarse, a finales de la década de los cincuenta. Según Dueñas, Medina, Ramírez, Camacho y Sobenis (2019) el concepto es acuñado por el pensador francés Gaston, el cual fundamenta el principio de que el futuro depende de las acciones del hombre en el presente.

La prospectiva, según Michel Godet "se enfoca en el presente dando significado a la acción, pero acción sin meta no tiene sentido" (Tapia, 2016). Es la intersección de tres campos: estudios de futuro, planificación estratégica y análisis de políticas, es decir va desde: lo predictivo, pasivo extrapolatorio hacia: lo exploratorio, activo y constructivo (Gavigan y Scapolo, 2000).

La utilización de la prospectiva en el análisis externo o análisis del entorno de los procesos de planificación, planeamiento o planeación estratégica es clave a la hora de la identificación de tendencias y su impacto en el sistema analizado, en la elaboración escenarios, en la identificación de factores de éxito futuros, o en la reflexión estratégica y en la formulación de estrategias (Astigarraga, 2016). 
Actualmente, los autores se refieren a la planeación prospectiva estratégica, pues esta se dirige a la acción concreta, es saber hacia dónde se va. Miklos y Tello, plantean que sostiene una visión holística en lugar de parcial y desintegrada: además de aspectos cuantitativos, considera aquellos de naturaleza cualitativa, lo cual permite así una apreciación más completa; sus relaciones son más dinámicas y están basadas en estructuras evolutivas y no fijas 0 estáticas; su futuro es múltiple e incierto; lo más importante: su actitud hacia el futuro es activa y creativa y no pasiva o sencillamente adaptativa (Montoya y Bedoya, 2018).

Al analizar los conceptos enunciados anteriormente, se puede concluir que la prospectiva estratégica es concebida como una herramienta utilizada como parte del proceso de planificación; guía las acciones del presente en pos de construir un futuro probable para la organización, la cual aporta elementos muy importantes para la toma de decisiones.

La actitud activa y creativa hacia el futuro de las empresas, como parte de la planeación estratégica prospectiva, incluye la elaboración de escenarios como un elemento clave de este proceso.

Godet y Durance (2011) afirman que un escenario es un conjunto de elementos que describen una situación futura, y una ruta de eventos que permiten a la entidad moverse desde la situación actual a una futura (Gándara, 2015).

Bas (citado en Hernández, 2020) plantea que un escenario es un futurible (un futuro posible), de entre varias alternativas, que describe una situación hipotética futura. En forma análoga, Godet citado en Perilla y González (2017) plantea que un escenario es "un conjunto formado por la descripción de una acción futura y un camino de acontecimientos que permiten pasar de una situación original a otra futura".

Salas (2013) define la construcción de escenarios como un método que posibilita ordenar las percepciones acerca de los entornos futuros alternativos que pueden afectar un territorio, en este sentido, el diseño de escenarios se constituye como "un proceso sistemático para esbozar el futuro a largo plazo de una ciudad o de un territorio mediante la reflexión estratégica" (Fernández, 2012).

Bajo esta perspectiva, el método de escenarios se ha revelado sumamente productivo, al permitir a la empresa adaptarse a los cambios y situaciones contingentes al aprovechar las posibilidades latentes en éstos, confiriéndole, en muchos casos, una ventaja competitiva, erigiéndose en una técnica que se ha comprobado consistentemente efectiva para enfrentar la incertidumbre estratégica en numerosas compañías, en diversas industrias.

Los trabajos académicos y de consultoría relacionados con la prospectiva turística han sido 
muy escasos en los últimos años. Una búsqueda reciente en la European Foresight Platform, programa financiado por la Comisión Europea que ha documentado cerca de 500 ejercicios de prospectiva en todo el mundo, develó que sus archivos solo contaban con un caso de estudio en el cual se habían diseñado escenarios de futuro para la actividad turística (Mittringer citado en Hernández, 2020). Asimismo, son escasos los artículos aparecidos en las revistas especializadas en prospectiva relativos a temáticas turísticas.

Como afirman Vergara, Fontalvo, y Maza, (2010), son numerosas y trascendentes las razones que aconsejan incorporar la prospectiva en los procesos de planificación turística. Este nivel de complejidad viene dado por la propia organización del sector, el cual agrupa cada uno de los elementos en dos grandes subsistemas: endógenos y exógenos (Martín, 2010).

En Cuba, se han dado pasos de avances en cuanto a la planeación estratégica de los diferentes sectores de la nación, con vistas al año 2030, pero aún se carecen de estos estudios en el sector del turismo, y en específico en las empresas de intermediación turística.

Un papel fundamental dentro del desarrollo del turismo y los destinos turísticos, es el rol que desempeñan las empresas de intermediación en la unificación de los diferentes factores que conforman la red de comercialización del producto turístico, debido en gran medida, a que son entidades que organizan servicios turísticos diversos, ya que facilitan, la distribución de un conjunto de servicios ofrecidos por otras empresas. Constituyen el enlace principal, en muchas ocasiones, y necesariamente imprescindibles entre la oferta y la demanda turística (Martínez y Baeza, 2016).

El principal rol como empresas de intermediación lo constituyen las agencias de viajes. Una vez analizado los conceptos propuestos por diferentes autores, Rodríguez, Viamonte, Hernández, Sánchez y Velasteguí (2019), afirman que "constituyen una empresa mercantil, las cuales tiene como propósito brindar al cliente servicios relacionados con el turismo, por medio de sus diferentes funciones (...) jugando un rol mediador entre la persona que demanda el servicio y el productor (...)."

Si se analiza el Modelo Pentagonal del Sistema Turístico de Martín (2010), en cuanto al lugar que ocupan las AA.VV. como empresas mercantiles y de servicios, su interrelación con el resto de los elementos de los subsistemas endógenos, exógenos y el macroentorno, así como la nueva estructura establecida en Cuba que provoca la existencia de incertidumbre en cuanto a la complejidad de escenarios a los cuales pueden enfrentarse las AA.VV. a mediano y largo plazo, y sumando la competencia generada por AA.VV. de los destinos cercanos, se hace evidente la necesidad de realizar estudios de prospectiva estratégica en aras de que se puedan establecer 
acciones estratégicas que permitan el cumplimiento de los objetivos trazados por cada empresa y lograr con ello la diferenciación del resto. Se evidencia además la necesidad de conocer y aplicar los métodos más efectivos para estos estudios.

\section{MATERIALES y MÉTODOS}

Desde sus inicios, para la construcción de escenarios se han desarrollado diferentes metodologías catalogadas en tres grandes escuelas: la lógica e intuitiva, la prospectiva y de tendencia probabilística (Bradfield et al, citado en Hernández, 2020).

Según Chermack, Lynham y Ruona (2001), la primera de ellas fue propuesta por Herman Kahn en 1967 y se caracterizaba por ser un esquema totalmente cualitativo basado más en la intuición y juicios de valor, que en un soporte científico.

Las metodologías para la planeación por escenarios han evolucionado, integrándose la toma de decisiones y estrategias para aprovechar mejor los escenarios creados (Conway, 2004).

Vergara, Fontalvo y Maza (2010), realizan un listado cronológico resumen de las metodologías desarrolladas para la construcción de escenarios. De todas las metodologías analizadas, la más conocida y utilizada a nivel internacional es la presentada por Michael Godet, en el año 1992 (la cual ha sido modificada por el propio autor, adaptándola a los contextos actuales), como representante de la escuela prospectiva, pues propone que "los escenarios pueden servir no solo para predecir un futuro, sino como orientación para construir un futuro idealizado, integrándola como herramienta en los estudios prospectivos estratégicos" (Godet y Durance, 2007).

Para el desarrollo de esta metodología, se cuenta además con el apoyo que ofrecen los métodos informáticos y estadísticos desarrollados por el Laboratorio de Investigación de Prospectiva Estratégica y Organización (LIPSOR).

El estudio se dividió en tres fases, luego de la adaptación de la metodología para la construcción de escenarios, propuesta por Michael Godet al estudio a realizar (Tabla 1).

Tabla 1

Proceso metodológico de la investigación

\begin{tabular}{lll}
\hline \multicolumn{1}{c}{ Fases } & \multicolumn{2}{c}{ Proceso metodológico } \\
\hline Fase 1: Construcción de la & \multicolumn{1}{c}{ Etapa 1: Delimitar el sistema y y } & Análisis estratégico de la técnicas y herramientas \\
base & su entorno & organización: Matriz de Evaluación \\
& & de Factores Interno (MEFI) y la Matriz \\
& de Evaluación de Factores Externos \\
& $($ MEFE) \\
\hline
\end{tabular}




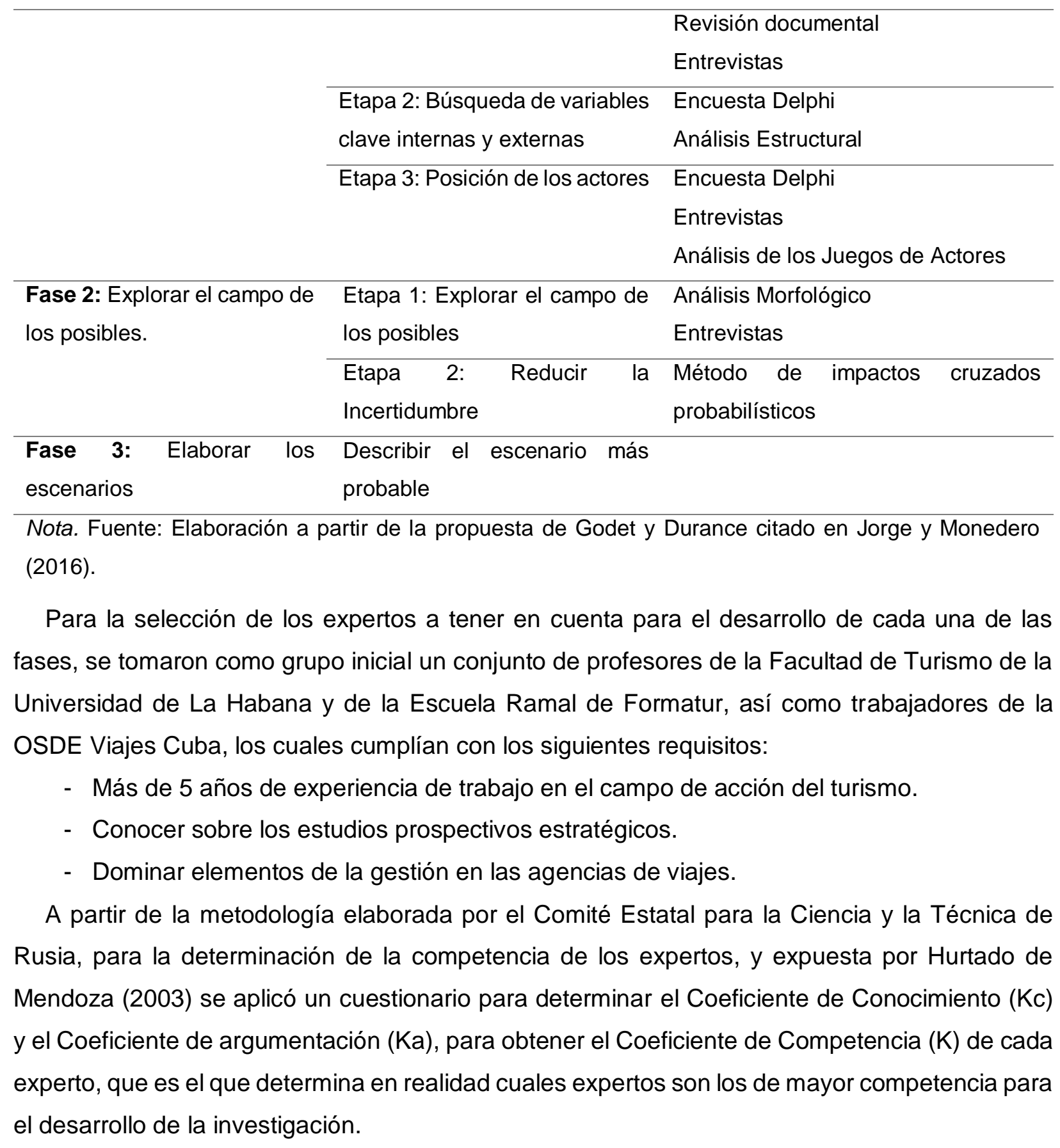

\section{ANÁLISIS Y DISCUSIÓN DE LOS RESULTADOS}

\section{Fase 1: Construcción de la base}

La OSDE Viajes Cuba, no sustituye la actividad comercial de las agencias, ya que estas conservan su independencia contractual y de comunicación. En esencia, la labor de esta empresa consiste en garantizar una adecuada supervisión y control de los diferentes procesos y 
actividades de las agencias de viajes asociadas.

La unión de las cuatro agencias de viajes principales de Cuba en un solo organismo, proporciona a la OSDE un amplio poder negociador que permitiría obtener mejores condiciones en los contratos con los prestatarios extranjeros.

Para el desarrollo de esta investigación se analizará la OSDE como la unión de las cuatro agencias $y$, por ende, con cada una de sus funciones como prestatarias de servicios: mediadora, productora y asesora/asistencia (Ayala, 2017).

\section{Etapa 1: Delimitación del sistema y su entorno}

Al analizar el documento elaborado en la entidad objeto de estudio: Planeación Estratégica (2017-2022), se evidencian brechas en la formulación de algunos de sus elementos con los elementos teóricos a tener en cuenta para su diseño.

Según Aguirre, Morales y Olivera (2017), la declaración de la misión de una entidad, guía y orienta al personal y a los socios estratégicos sobre cuál es la naturaleza de la actividad de la organización; facilita a la organización del funcionamiento coherente como una unidad, por lo que una declaración de misión bien planteada debe emplear un lenguaje específico para revelar la identidad propia de la compañía. Es por ello que, la entidad debe poseer una misión que sea lo bastante descriptiva para identificar los productos o servicios de la compañía, especificar las necesidades de los segmentos que atiende, evidenciar el enfoque hacia los clientes y otorgar su propia identidad a la empresa (Thompson et al., 2012).

La misión definida actualmente no refleja cada uno de los elementos anteriores, lo que igual sucede con la visión, la cual es la imagen de un futuro ambicioso y deseable que está relacionado con los sueños a largo alcance de la empresa (Aguirre, Morales y Olivera, 2017).

Según Prieto (2012), la visión debe incluir diferentes elementos como: el horizonte (definida en el tiempo y teniendo en cuenta el medio en que se desarrolla la organización); compromiso (apoyada y compartida por el equipo gerencial y sus colaboradores); amplitud (lenguaje que permita actuar e identificar los objetivos escogidos para la empresa); significado (refleja el sentido de pertenencia hacia la entidad); realismo (sueño posible y no una ilusión) y debe ser sinérgica (en consonancia con la filosofía de la organización).

Se puede afirmar entonces que, tanto la misión como la visión establecidas actualmente por la OSDE Viajes Cuba, carecen de elementos idóneos para su definición, y, en consecuencia, el resto de los elementos de la planificación estratégica se realizan en base a estos errores.

Otro elemento expuesto en Viajes Cuba S.A. (2016), es la definición de escenarios para el 
desarrollo del turismo en Cuba. Nuevos elementos a tener en cuenta para cada escenario (definido) es la evolución del sector privado como factor influyente, pues desempeña un papel clave en el turismo en Cuba en los últimos años; así como los cambios de la política de Estados Unidos (EE.UU.) hacia nuestro país.

Dentro del análisis estratégico, un papel fundamental lo desempeña la correcta identificación de las fortalezas y debilidades internas, pues son las actividades que una organización puede controlar y que desempeña de forma correcta o con deficiencias. Estas debilidades y fortalezas surgen a partir del análisis de las actividades empresariales como la administración, marketing, finanzas y contabilidad, producción y operaciones, la investigación y desarrollo, así como los sistemas de información (Aguirre, Morales y Olivera, 2017).

En el análisis presentado por la OSDE, las fortalezas y debilidades no contemplan todos los elementos enunciados anteriormente. Dentro de las fortalezas, no especifican el tipo de mercado o cuota en la que participan, es decir, el alcance que este tenga (nacional y/o internacional), consideran la existencia de un esquema externo propio, lo cual no está redactado coherentemente, y sería correcto plantearlo como: Existencia de un esquema interno propio, haciendo referencia a la forma de su estructura organizacional, establecida de tal forma que facilita la gestión empresarial de la OSDE.

Una de las debilidades definidas es la insuficiente preparación del Capital Humano, lo cual no debería ser considerada como tal, ya que es una organización donde las empresas que lo integran presentan experiencia en el sector, elemento que incluso reconocen como su principal ventaja competitiva.

Por otra parte, las oportunidades y amenazas se refieren a las tendencias y acontecimientos económicos, sociales, culturales, demográficos, ambientales, políticos, legales, gubernamentales, tecnológicos y competitivos que pueden beneficiar o perjudicar significativamente a una organización en el futuro (Aguirre, Morales y Olivera, 2017).

En el análisis realizado por la entidad, al definir las amenazas, no se tiene en cuenta la inestabilidad del sector externo, del que Cuba no está ajena, la volatilidad de los mercados internacionales y las condiciones particulares a las que está sometido el país, dadas las características del bloqueo económico - financiero y su recrudecimiento luego del gobierno actual de los EE.UU.

En la definición de las oportunidades, existen elementos de ambigüedad, como es el caso de las mencionadas políticas de restauración, donde no es completamente clara la información, ya que no exponen cuáles serían dichas políticas, ni en qué medida los favorecería, lo cual 
justificaría el hecho de que sean consideradas oportunidades para la organización.

Por estas razones, identificar, examinar y evaluar de forma correcta las fortalezas, debilidades, oportunidades y amenazas de la OSDE Viajes Cuba es esencial para la formulación correcta del resto de los elementos de la planificación estratégica de la entidad, lo que permitirá el establecimiento de una guía coherente para con sus objetivos estratégicos, haciendo más eficiente la gestión de los servicios de la entidad.

Con el criterio de los especialistas entrevistados, se construyó la Matriz de Evaluación de los Factores Externos (MEFE), que permite a los estrategas resumir y evaluar información políticalegal, económica, social-cultural, tecnológica, ecológica y competitiva de la OSDE Viajes Cuba.

Tabla 2

MEFI - OSDE Viajes Cuba

\begin{tabular}{|c|c|c|c|c|c|c|c|}
\hline \multicolumn{2}{|r|}{ Factor Político } & \multicolumn{3}{|c|}{ Oportunidad } & \multicolumn{3}{|c|}{ Amenaza } \\
\hline & & Alto & Medio & Bajo & Alto & Medio & Bajo \\
\hline 1 & Lineamientos del PCC & $\mathrm{X}$ & & & & & \\
\hline 2 & $\begin{array}{l}\text { Seguridad como atributo del } \\
\text { destino }\end{array}$ & $\mathrm{X}$ & & & & & \\
\hline \multirow[t]{3}{*}{3} & $\begin{array}{l}\text { Efecto Bloqueo Económico y } \\
\text { comercial impuesto por EE.UU. }\end{array}$ & & & & $X$ & & \\
\hline & \multirow[t]{2}{*}{ Factor Económico } & \multicolumn{3}{|c|}{ Oportunidad } & \multicolumn{3}{|c|}{ Amenaza } \\
\hline & & Alto & Medio & Bajo & Alto & Medio & Bajo \\
\hline 1 & Poder adquisitivo de los clientes & & $\mathrm{X}$ & & & & \\
\hline 2 & $\begin{array}{l}\text { Peso medio gastado por los } \\
\text { visitantes en el destino }\end{array}$ & & $\mathrm{X}$ & & & & \\
\hline 3 & $\begin{array}{l}\text { Inestabilidad en la situación } \\
\text { económica de los países emisores }\end{array}$ & & & & $X$ & & \\
\hline 4 & Dualidad monetaria & & & & & $\mathrm{X}$ & \\
\hline \multirow{2}{*}{\multicolumn{2}{|c|}{ Factor Social }} & \multicolumn{3}{|c|}{ Oportunidad } & \multicolumn{3}{|c|}{ Amenaza } \\
\hline & & Alto & Medio & Bajo & Alto & Medio & Bajo \\
\hline 1 & Número de visitantes al destino & & $\mathrm{X}$ & & & & \\
\hline 3 & $\begin{array}{l}\text { Nivel promedio de educación de los } \\
\text { visitantes }\end{array}$ & & $\mathrm{X}$ & & & & \\
\hline 4 & Acogida Comunidad local & $\mathrm{X}$ & & & & & \\
\hline 5 & Disponibilidad tiempo para viajar & $X$ & & & & & \\
\hline & Factor Tecnológico & & portuni & & & Amenaz & \\
\hline
\end{tabular}




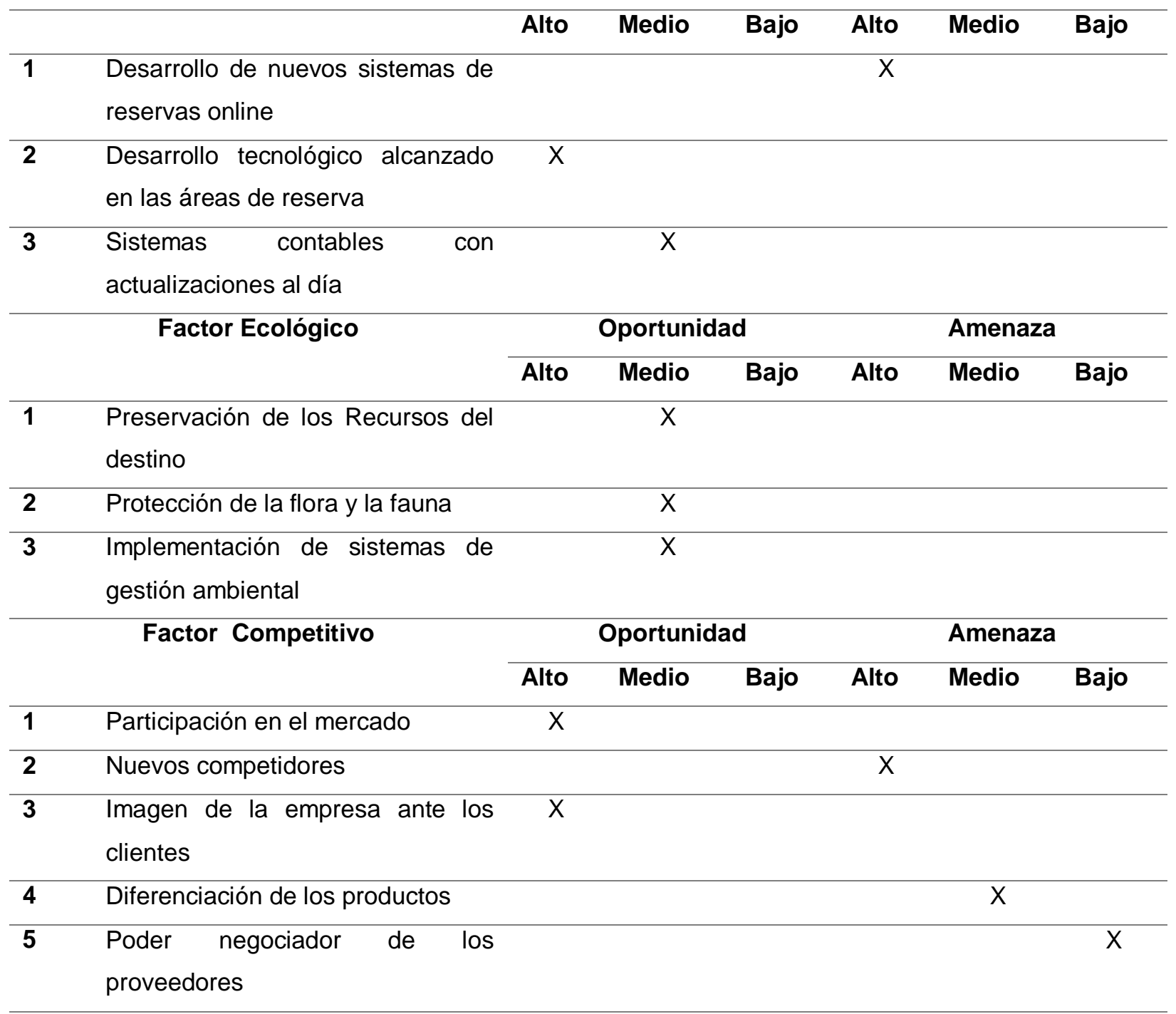

Nota. Fuente: Elaboración propia

De igual forma, se construyó la Matriz de Evaluación de Factor Interno (MEFI), la cual proporciona una base para analizar las relaciones internas entre las áreas de las empresas que conforman la OSDE Viajes Cuba.

Tabla 3

MEFI - OSDE Viajes Cuba

\section{Administración}

Debilidad

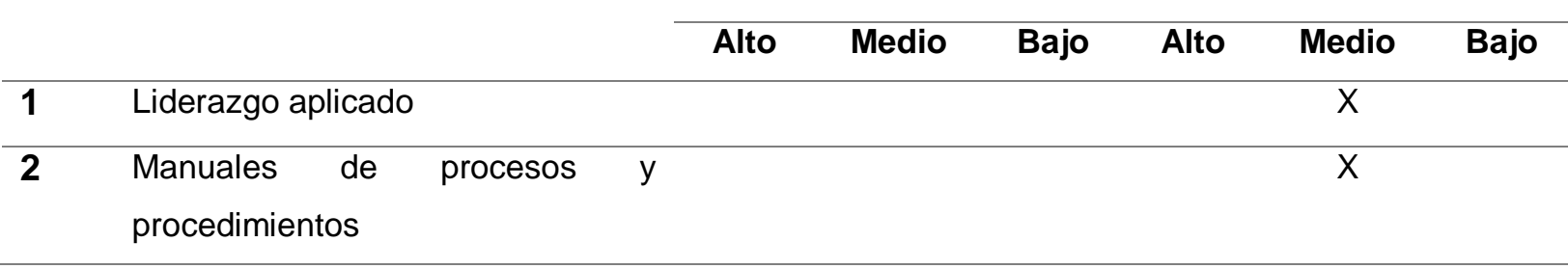




\section{Marketing y ventas}

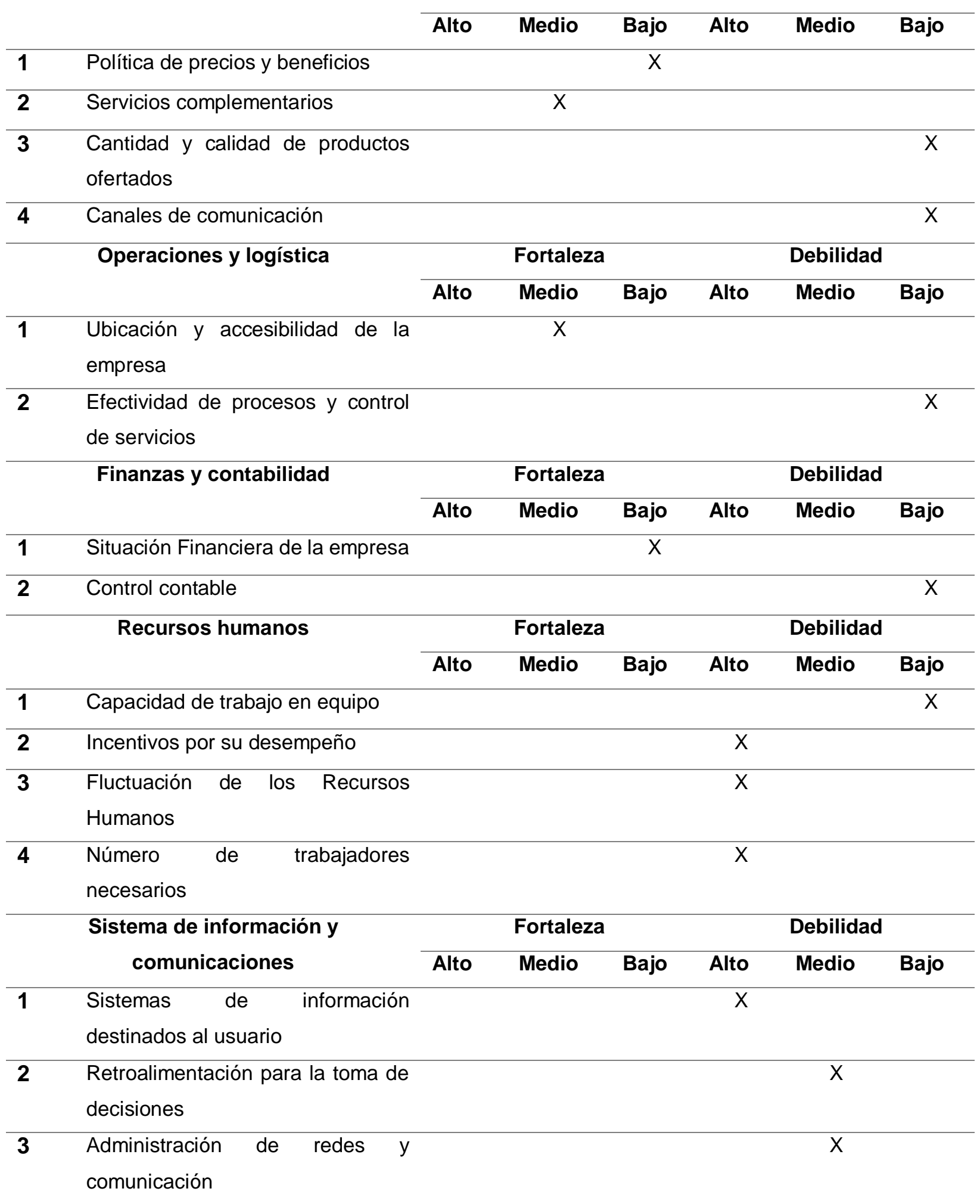

Tecnología, innovación y

desarrollo

\begin{tabular}{llllll}
\multicolumn{3}{c}{ Fortaleza } & \multicolumn{3}{c}{ Debilidad } \\
\hline Alto & Medio & Bajo & Alto & Medio & Bajo
\end{tabular}




\begin{tabular}{|c|c|c|}
\hline 1 & $\begin{array}{l}\text { Investigación y desarrollo de } \\
\text { procesos y servicios }\end{array}$ & $X$ \\
\hline 2 & $\begin{array}{l}\text { Capacidad para adquirir nuevas } \\
\text { tecnologías }\end{array}$ & $X$ \\
\hline 3 & $\begin{array}{l}\text { Implementación de las tecnologías } \\
\text { de la información y las } \\
\text { comunicaciones (TIC) en la gestión } \\
\text { de los procesos }\end{array}$ & $X$ \\
\hline 4 & $\begin{array}{l}\text { Implementación de los sistemas de } \\
\text { gestión de las agencias de viajes }\end{array}$ & $X$ \\
\hline
\end{tabular}

Nota. Fuente: Elaboración propia.

\section{Etapa 2: Búsqueda de variables clave internas y externas}

A partir de la consulta a los expertos definidos para el desarrollo de la investigación, y con los resultados del análisis de la etapa 1 , se seleccionaron un total de 27 variables, de ellas un total de 11 de carácter externo y 16 que inciden de forma interna en la gestión de las agencias de viajes.

Tabla 4

Variables que inciden en la gestión de las agencias de viajes

\begin{tabular}{|c|c|c|c|}
\hline $\mathbf{N}^{\circ}$ & VARIABLE & DESCRIPCIÓN & TEMA \\
\hline 1 & $\begin{array}{l}\text { Desarrollo sistemas de reservas } \\
\text { online }\end{array}$ & $\begin{array}{l}\text { Integración de los sistemas de gestión de agencias } \\
\text { de viajes con el comercio electrónico, para disminuir } \\
\text { los efectos de la competencia generadas por las } \\
\text { agencias de viajes online. }\end{array}$ & Externa \\
\hline 2 & $\begin{array}{l}\text { Imagen de la empresa ante los } \\
\text { clientes }\end{array}$ & Imagen pública de la empresa & Externa \\
\hline 3 & $\begin{array}{l}\text { Preservación de los recursos del } \\
\text { destino }\end{array}$ & $\begin{array}{l}\text { Estado de conservación de los recursos naturales y } \\
\text { antrópicos del destinos utilizados para el desarrollo } \\
\text { de los productos }\end{array}$ & Externa \\
\hline 4 & Acogida comunidad local & $\begin{array}{l}\text { Nivel de educación de la población local donde se } \\
\text { desarrollan las actividades programadas por las } \\
\text { agencias }\end{array}$ & Externa \\
\hline 5 & Política económica del destino & $\begin{array}{l}\text { Leyes y resoluciones vigentes para la actividad } \\
\text { empresarial en Cuba; política de Inversiones; } \\
\text { política monetaria y cambiaria del destino }\end{array}$ & Externa \\
\hline
\end{tabular}


6 Bloqueo económico comercial Impactos negativos ocasionados al sector: Externa impuesto por EE.UU. limitaciones para el desarrollo de la infraestructura necesaria e impactos directo a los viajes

\begin{tabular}{|c|c|c|}
\hline 7 & $\begin{array}{l}\text { Desarrollo tecnológico } \\
\text { alcanzado en las áreas de } \\
\text { reserva }\end{array}$ & $\begin{array}{l}\text { Aprovechamiento de las nuevas TIC's en los Externa } \\
\text { sistemas de reserva en las agencias }\end{array}$ \\
\hline 8 & Sistemas de gestión ambiental & $\begin{array}{l}\text { Implementación en las instalaciones y zonas } \\
\text { turísticas de las leyes y resoluciones vigentes para } \\
\text { la conservación del patrimonio natural }\end{array}$ \\
\hline 9 & Disponibilidad tiempo para viajar & $\begin{array}{l}\text { Tendencia a realizar turismo durante espacios de } \\
\text { tiempos cortos, pero con mayor frecuencia }\end{array}$ \\
\hline 10 & $\begin{array}{l}\text { Seguridad como atributo del } \\
\text { destino }\end{array}$ & $\begin{array}{l}\text { Estabilidad política en los destinos turísticos del } \\
\text { país }\end{array}$ \\
\hline 11 & Nuevos competidores & $\begin{array}{l}\text { Competencia generada por los prestatarios de Externa } \\
\text { servicios privados. }\end{array}$ \\
\hline 12 & Calidad de productos ofertados & $\begin{array}{l}\text { Productos con altos estándares de calidad para Interna } \\
\text { competir en el mercado }\end{array}$ \\
\hline 13 & Capacidad de trabajo en equipo & $\begin{array}{l}\text { Capacidad para establecer las conexiones entre las } \\
\text { diferentes áreas de trabajo }\end{array}$ \\
\hline 14 & $\begin{array}{l}\text { Incentivos por el desempeño a } \\
\text { los trabajadores }\end{array}$ & Estimulo moral y material a los trabajadores \\
\hline 15 & $\begin{array}{l}\text { Implementación de las TIC en la } \\
\text { gestión de los procesos }\end{array}$ & Uso de las nuevas TIC en las agencias de viajes \\
\hline 16 & Liderazgo aplicado & $\begin{array}{l}\text { Tipo de dirección empleado en cada una de las } \\
\text { agencias }\end{array}$ \\
\hline 17 & Canales de comunicación & Amplitud y alcance de los canales de comunicación \\
\hline 18 & $\begin{array}{l}\text { Capacidad para adquirir nuevas } \\
\text { tecnologías }\end{array}$ & $\begin{array}{l}\text { Atendiendo a los gastos de la empresa y su } \\
\text { capacidad de invertir en infraestructura tecnológica. }\end{array}$ \\
\hline 19 & $\begin{array}{l}\text { Implementación de los Sistema } \\
\text { de Gestión en las AAVV }\end{array}$ & $\begin{array}{l}\text { Integración del mismo sistema de gestión en las } \\
\text { cuatro agencias de viajes }\end{array}$ \\
\hline 20 & $\begin{array}{l}\text { Retroalimentación para la toma } \\
\text { de decisiones }\end{array}$ & $\begin{array}{l}\text { Asociado a la participación de todos los niveles en } \\
\text { la toma de decisiones }\end{array}$ \\
\hline 21 & $\begin{array}{l}\text { Investigación y desarrollo de } \\
\text { procesos y servicios }\end{array}$ & Papel del grupo de $\mathrm{I}+\mathrm{D}+\mathrm{i}$ \\
\hline 22 & Política de precios y beneficios & $\begin{array}{l}\text { Estrategia de precios y poder de negociación con } \\
\text { los clientes }\end{array}$ \\
\hline
\end{tabular}




\begin{tabular}{|c|c|c|c|}
\hline 23 & $\begin{array}{l}\text { Administración de redes y } \\
\text { comunicación }\end{array}$ & $\begin{array}{l}\text { Efectividad del proceso de comunicación interna } \\
\text { entre las áreas de las AAVV }\end{array}$ & Interna \\
\hline 24 & $\begin{array}{l}\text { Manuales de procesos y } \\
\text { procedimientos }\end{array}$ & $\begin{array}{l}\text { Correcto diseño y funcionamiento de los procesos y } \\
\text { procedimientos en las diferentes áreas de las } \\
\text { agencias de viajes, acorde al desarrollo tecnológico } \\
\text { alcanzado a nivel internacional. }\end{array}$ & Interna \\
\hline 25 & Control contable & $\begin{array}{l}\text { Automatización de los procesos contables, y la } \\
\text { unicidad del mismo en las cuatro AAVV }\end{array}$ & Interna \\
\hline 26 & $\begin{array}{l}\text { Situación financiera de la } \\
\text { empresa }\end{array}$ & Utilidad Neta de la OSDE & Interna \\
\hline 27 & $\begin{array}{l}\text { Sistemas de información } \\
\text { destinados al usuario }\end{array}$ & Actualidad y veracidad de la información ofrecida & Interna \\
\hline
\end{tabular}

Nota. Fuente: Elaboración propia.

Al ser introducidas las variables en el software MICMAC (versión 6.1.2 2003/2004), y teniendo en cuenta la calificación otorgada por el grupo de expertos, y de la relación entre cada una de ellas, se establece una jerarquía de las variables estudiadas (Figura 1).

Plano de influenciass / dependencias indirectas potenciales

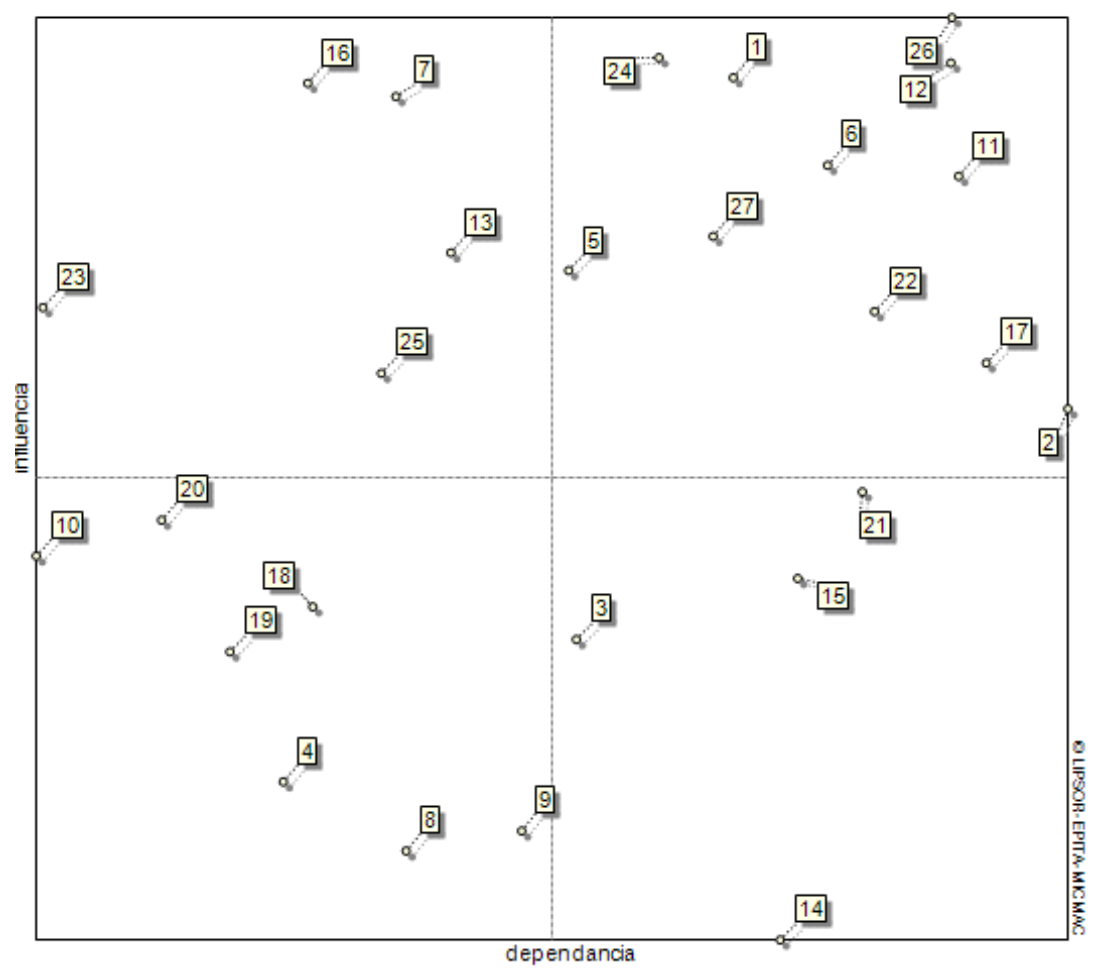

Figura 1. Plano de influencias/dependencias indirectas potenciales de las variables que inciden en la gestión de los servicios de la OSDE Viajes Cuba.

Nota. Fuente: Elaboración propia en el software MICMAC. 
Clasificadas cada una de las variables, y con la opinión de los expertos, en la tabla 5 se definen las variables claves (aquellas muy motrices y muy dependientes que influyen en la gestión de los servicios de las agencias de la OSDE Viajes Cuba).

Tabla 5

Variables claves que inciden en la gestión de los servicios de la OSDE Viajes Cuba

\begin{tabular}{|c|c|}
\hline Variables Claves & Descripción \\
\hline V1. Desarrollo sistemas de reservas online & $\begin{array}{l}\text { Integración de los sistemas de gestión de } \\
\text { agencias de viajes con el comercio } \\
\text { electrónico, para disminuir los efectos de la } \\
\text { competencia generadas por las agencias de } \\
\text { viajes online. }\end{array}$ \\
\hline V5. Política económica del destino & $\begin{array}{l}\text { Leyes y resoluciones vigentes para la } \\
\text { actividad empresarial en Cuba; política de } \\
\text { Inversiones; política monetaria y cambiaria } \\
\text { del destino. }\end{array}$ \\
\hline $\begin{array}{l}\text { V6. Bloqueo económico comercial impuesto } \\
\text { por EE.UU. }\end{array}$ & $\begin{array}{l}\text { Impactos negativos ocasionados al sector: } \\
\text { limitaciones para el desarrollo de la } \\
\text { infraestructura necesaria e impactos directo a } \\
\text { los viajes. }\end{array}$ \\
\hline V11. Nuevos competidores & $\begin{array}{l}\text { Competencia generada por los prestatarios } \\
\text { de servicios privados. }\end{array}$ \\
\hline V12. Calidad de productos ofertados & $\begin{array}{l}\text { Productos con altos estándares de calidad } \\
\text { para competir en el mercado }\end{array}$ \\
\hline V17. Canales de comunicación & $\begin{array}{l}\text { Amplitud y alcance de los canales de } \\
\text { comunicación }\end{array}$ \\
\hline $\begin{array}{l}\text { V21. Investigación y desarrollo de procesos } \\
\text { y servicios }\end{array}$ & Papel del grupo de I+D+i \\
\hline V22. Política de precios y beneficios & $\begin{array}{l}\text { Estrategia de precios y poder de negociación } \\
\text { con los clientes }\end{array}$ \\
\hline $\begin{array}{l}\text { V24. Manuales de procesos y } \\
\text { procedimientos }\end{array}$ & $\begin{array}{l}\text { Correcto diseño y funcionamiento de los } \\
\text { procesos y procedimientos en las diferentes } \\
\text { áreas de las agencias de viajes, acorde al } \\
\text { desarrollo tecnológico alcanzado a nivel } \\
\text { internacional. }\end{array}$ \\
\hline
\end{tabular}




$\begin{array}{ll}\text { V27.Sistemas de información destinados al } & \begin{array}{l}\text { Actualidad y veracidad de la información } \\ \text { ofuario }\end{array} \\ & \text { ofrecida en los diferentes medios de } \\ & \text { promoción y distribución. }\end{array}$

Nota. Fuente: Elaboración propia.

\section{Etapa 3: Posición de los actores}

En esta etapa se identifican empresas, organismos o instituciones de cualquier índole, que ejercen en mayor o menor grado, una influencia sobre las variables clave de futuro identificadas y se denominan como actores. Tras la consulta a los expertos, se determinaron un total de nueve actores.

Posteriormente, construida la Matriz de Influencias Directas entre los Actores (MIDA), cada uno de estos es ubicado en el plano de influencia y dependencia (Figura 2).

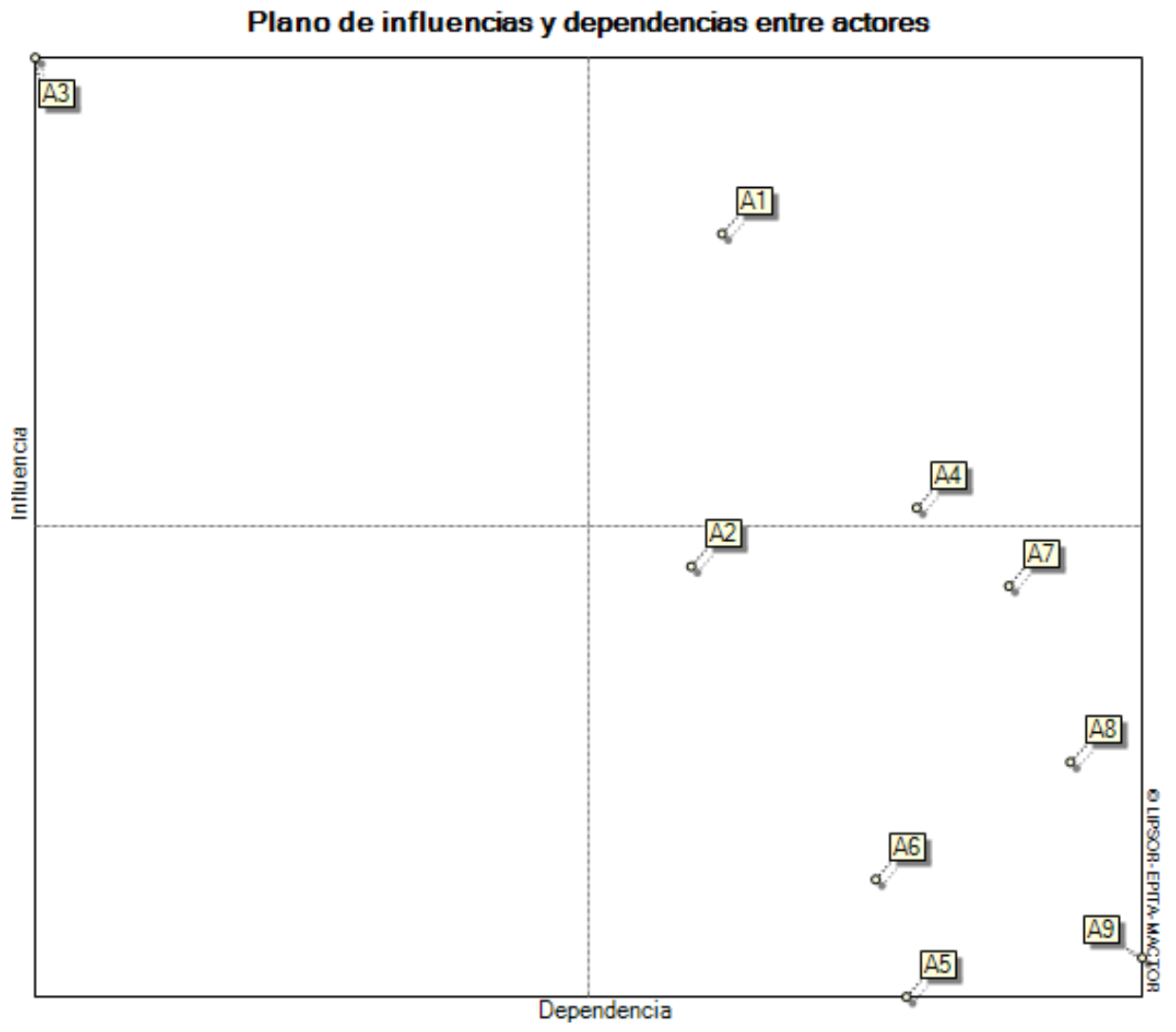

Figura 2. Plano de influencias/dependencias entre los actores que inciden en las variables claves identificadas.

Fuente: Elaboración en el software MACTOR (Versión 5.1.2 - 2003/2004).

A partir del gráfico anterior, cada uno de los actores es clasificado atendiendo a su nivel de dependencia e influencia. 
En el primer cuadrante se encuentran los actores denominados de "enlace", es decir, aquellos que son al mismo tiempo influyentes en la problemática y dependen de ella: el MINTUR (A1) y la Dirección de perfeccionamiento y control de la OSDE (A4).

En el segundo cuadrante se ubican los actores denominados como "dominantes", es decir aquellos que influyen en la problemática, pero no dependen de ella: Gobierno de EE.UU. (A3).

En el tercer cuadrante se ubican los actores "autónomos", es decir, o no son parte de la problemática o actúan agravándola. En el caso del presente estudio ninguno de los actores es clasificado de esta forma.

En el cuarto cuadrante se ubican los actores "dominados" es decir aquellos que dependen y se ven afectados por la problemática, pero no influyen mayormente en ella, sin embargo, se los debe considerar porque serán beneficiarios o afectados de la aplicación de la política: Ministerio de Economía y Planificación (A2); Dirección de tecnología y sistema de la OSDE (A5); Dirección de administración y logística de la OSDE (A6); Dirección de planificación y análisis económico de la OSDE (A7); Dirección de mercadotecnia de la OSDE (A8) y los Nuevos competidores (A9).

Para identificar el rol que desempeña cada uno de estos actores en la construcción de los escenarios futuros de la OSDE Viajes Cuba, se establecen (a partir de las variables claves identificadas) los retos de la organización al año 2025.

- Reto 1: Fortalecer el comercio electrónico en las AA.VV. de la OSDE, a través de la integración con los sistemas de gestión de agencias de viajes.

- Reto 2: Implementar herramientas para la automatización de los procesos en las agencias de viajes.

- Reto 3: Implementar políticas de innovación y desarrollo en todas las áreas de las agencias de viajes.

- Reto 4: Crear políticas de precios y beneficios para los clientes fidelizados en las agencias.

- Reto 5: Diseñar nuevos productos atendiendo a las necesidades de los segmentos de demanda meta de cada agencia de viajes.

- Reto 6: Establecer alianzas con nuevos medios de comunicación para la distribución de los productos y servicios de las agencias de viajes.

- Reto 7: Mantener actualizados los sistemas de información a los usuarios con información verídica de los productos y servicios de las agencias de viajes.

- Reto 8: Reforzar la infraestructura tecnológica disponible en las áreas de trabajo de las agencias de viajes. 
- Reto 9: Disminuir las importaciones para la prestación de los servicios, a través del uso de los encadenamientos productivos.

\section{Fase 2: Explorar el campo de los posibles y reducir la incertidumbre}

\section{Etapa 1: Explorar el campo de los posibles}

Al analizar los resultados de la Fase 1 de la investigación y con el criterio emitido por cada uno de los expertos, se diseñaron cuatro hipótesis (Tabla 6) que agrupan las tendencias de cada una de las variables claves identificadas, así como los retos diseñados para el 2025.

Tabla 6

Hipótesis diseñadas para la construcción de escenarios de la OSDE Viajes Cuba al año 2025.

\begin{tabular}{|c|c|c|}
\hline No. & Título largo & Descripción \\
\hline 1 & $\begin{array}{l}\text { Desarrollo } \\
\text { tecnológico }\end{array}$ & $\begin{array}{l}\text { Como resultado de la integración de los sistemas de gestión de agencias de } \\
\text { viajes con el comercio electrónico, se logra elevar los índices de satisfacción } \\
\text { de los clientes, obteniendo ventajas competitivas con respecto a la } \\
\text { competencia y con ello disminuir los efectos del bloqueo económico } \\
\text { comercial impuesto por los EEUU contra la isla. }\end{array}$ \\
\hline 2 & $\begin{array}{l}\text { Productos } \\
\text { calidad }\end{array}$ & $\begin{array}{l}\text { Con el trabajo realizado por el grupo de l+D+i de la OSDE se logra crear una } \\
\text { cultura de innovación en la gestión de las agencias de viajes, logrando } \\
\text { establecer altos estándares de calidad en los productos/servicios brindados } \\
\text { y, con ello, una alta diferenciación de la competencia. }\end{array}$ \\
\hline 3 & $\begin{array}{l}\text { Informatización } \\
\text { del trabajo }\end{array}$ & $\begin{array}{l}\text { Con la introducción de nueva infraestructura tecnológica, y la informatización } \\
\text { de los procesos, se logran actualizar los manuales de procesos y } \\
\text { procedimientos en las agencias, logrando con ello mantener actualizados } \\
\text { los sistemas de información destinados al usuario. }\end{array}$ \\
\hline 4 & $\begin{array}{l}\text { Aumento de la } \\
\text { competencia }\end{array}$ & $\begin{array}{l}\text { Se establecen nuevas regulaciones para la gestión de los servicios del } \\
\text { sector privado a los visitantes, por lo que las agencias deben aplicar nuevas } \\
\text { políticas de precios y beneficios con el objetivo de mantener un alto nivel de } \\
\text { fidelización de sus clientes, y aumentar sus canales de comunicación y } \\
\text { distribución de los productos/ servicios. }\end{array}$ \\
\hline
\end{tabular}

Nota. Fuente: Elaboración propia.

\section{Etapa 2: Reducir la Incertidumbre}

En la segunda etapa, con el procesamiento de la información a través de software Smic-ProbExpert (Versión 5.0 - 2004), y teniendo en cuenta que cada combinación de hipótesis diferentes, 
cumplidas o no, conforman un escenario, se construyen un total de 16 escenarios.

El grupo de expertos, le asigna la probabilidad simple de ocurrencia a cada una de las hipótesis diseñadas, y de igual forma la probabilidad condicionada (de acuerdo a la realización o la no realización de otra). De esta forma se elabora el Histograma de probabilidad de los escenarios (Figura. 3), el cual muestra la probabilidad de ocurrencia de cada escenario.

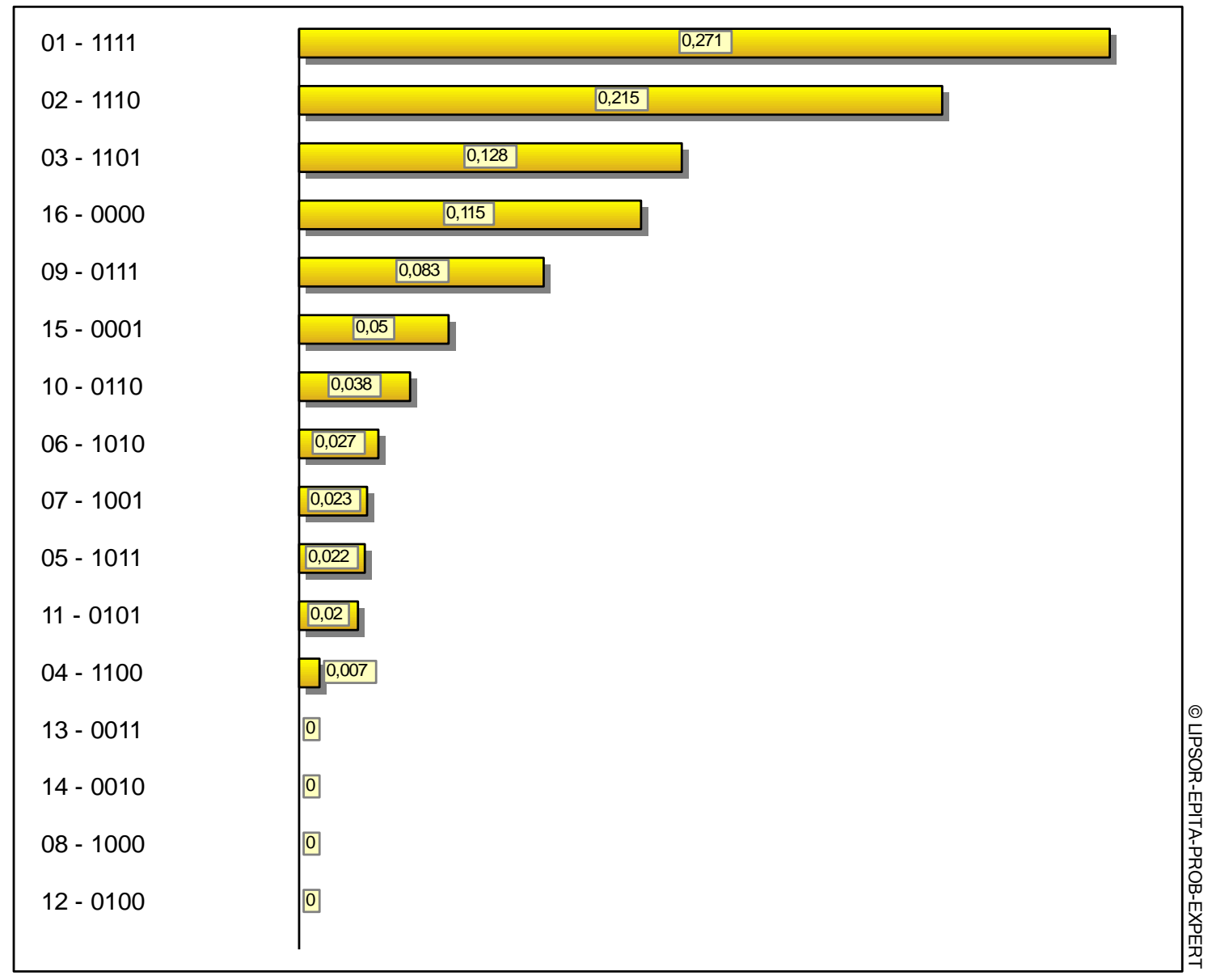

Figura 3: Histograma de probabilidad de los escenarios.

Fuente: Elaboración en el software Smic-Prob-Expert (Versión 5.0 - 2004).

Se observa, que el $50 \%$ de probabilidad de ocurrencia total de los escenarios se concentra en tres de los definidos $(1111 ; 1110 ; 1101)$, mientras que el cuarto escenario de mayor probabilidad es aquel no deseado por la entidad, pues implica que se mantendrán las condiciones actuales sin cambios significativos y que no se cumplen ningunas de las hipótesis planteadas.

\section{Fase 3: Elaborar los escenarios}

Escenario 1 (1111): se define entonces, como el escenario más probable para la OSDE Viajes Cuba al año 2025, con un $27,1 \%$ de probabilidad de ocurrencia el número 1 , que implica la 
ocurrencia de las cuatro hipótesis diseñadas, el cual constituye además el escenario deseado o apuesta de la entidad.

El escenario más probable, incluye una evolución favorable de la mayoría de las variables claves identificadas, teniendo en cuenta el rol de los actores involucrados y los retos diseñados para la entidad al año 2025. Implica la integración de los sistemas de gestión de agencias de viajes con el comercio electrónico, un arduo trabajo a realizar por el grupo de l+D+i de la OSDE, la introducción de una nueva infraestructura tecnológica, la actualización de los manuales de procesos y procedimientos en las agencias, y el diseño de productos/servicios con una mayor calidad, todo ello permite contrarrestar los efectos de la política hostil desarrollada por el gobierno de EE.UU. contra la isla y el aumento de la competencia.

De igual forma la introducción de estos cambios, contribuirá a la actualización de los sistemas de información destinados al usuario, obtener un mayor alcance de los canales de comunicación y diseñar nuevas políticas de precios y beneficios para los clientes.

Una vez, determinado el escenario más probable, se realizó un análisis de sensibilidad para determinar las hipótesis más motrices o dominantes, dentro de este escenario más probable, por lo que se establece que las acciones de mayor envergadura que debe realizar la OSDE Viajes Cuba deben estar encaminadas al cumplimiento de la hipótesis "Aumento de la competencia" pues es la hipótesis más dominante de las diseñadas, lo cual implica que puede ejercer gran influencia en el cumplimiento de las restantes.

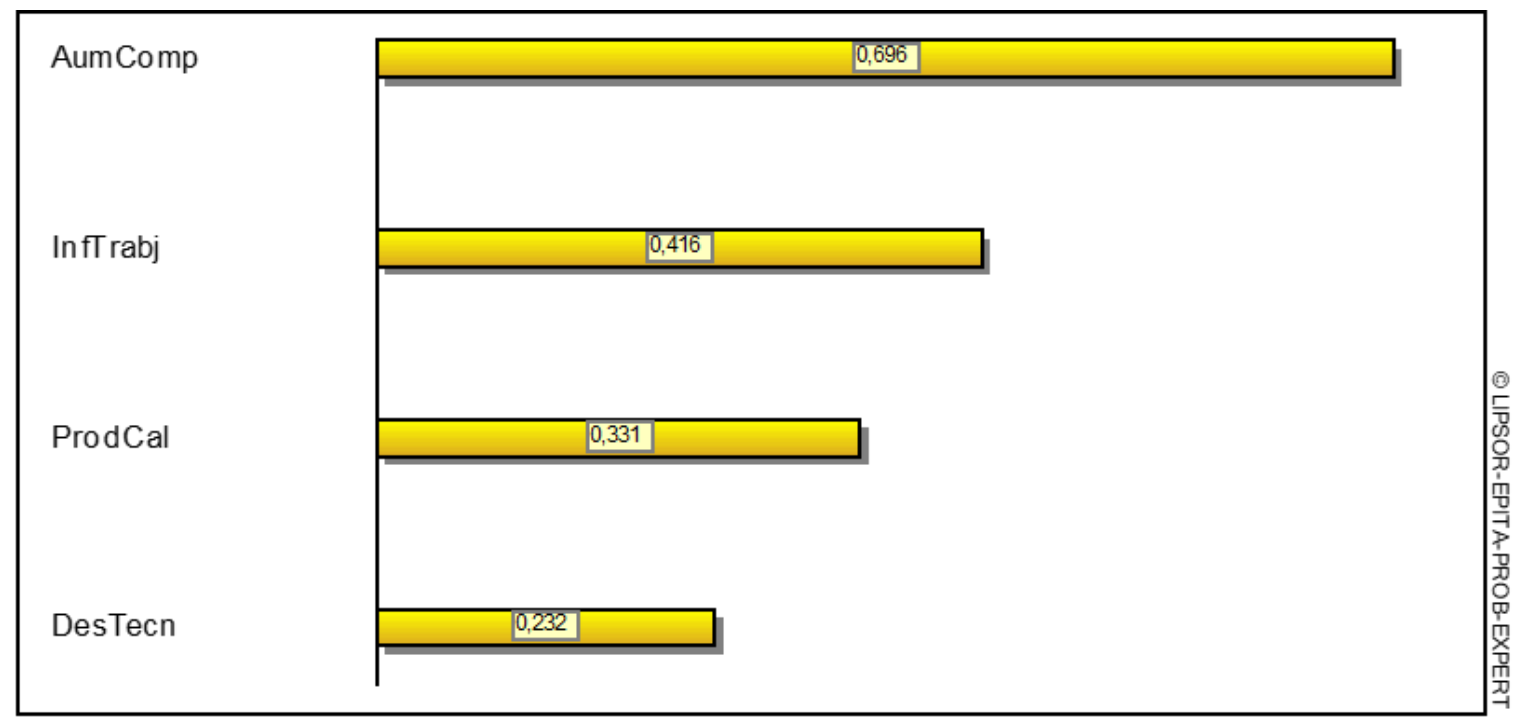

Figura. 4. Histograma de sensibilidad de las influencias.

Fuente: Elaboración en el software Smic-Prob-Expert (Versión 5.0 - 2004). 


\section{CONCLUSIONES}

Con el desarrollo de la presente investigación se pudo concluir que:

- La prospectiva estratégica es concebida como una herramienta utilizada como parte del proceso de planificación, en aras de construir un futuro probable para la organización.

- El método de construcción de escenarios prospectivos es una herramienta utilizada por las organizaciones para el manejo de la incertidumbre dentro del proceso de toma de decisiones y el de planificación estratégica prospectiva.

- La planeación estratégica actual de la OSDE Viajes Cuba, carece de una correcta formulación de algunos de sus elementos claves, lo que ha incido de forma negativa en el desarrollo de los procesos relacionados con la gestión de los servicios de las agencias de viajes.

- Al identificarse los factores que inciden en la gestión de los servicios de las agencias de viajes de la OSDE Viajes Cuba, y mediante la consulta a los expertos, se definieron un total de 10 variables claves y 9 actores, lo que permitió la evaluación de la influencia/ dependencia entre cada uno de ellos.

- Se diseñaron un total de 16 escenarios, a partir de la formulación de cuatro hipótesis vinculadas a las variables claves identificadas, definiendo como el escenario más probable el que incluye la combinación de la realización del total de las cuatro hipótesis.

- La investigación realizada contribuye a la planeación estratégica de la OSDE Viajes Cuba, y a la obtención de sus objetivos a largo plazo, así como la optimización de sus resultados económicos.

\section{REFERENCIAS BIBLIOGRÁFICAS}

Aguirre, K.P., Morales, H. y Olivera, D.C. (2017). Planificación Estratégica. Importancia de la formulación de la visión y la misión para el logro de los objetivos organizacionales. Nicaragua: Facultad de Ciencias Económicas.

Astigarraga, E. (2016). Prospectiva Estratégica: orígenes, conceptos clave e introducción a su práctica. Revista Centroamericana de Administración Pública. (71),13-29.

Ayala, H. (2017). Agencias de Viajes y Turoperadores en el turismo. La Habana: Félix Varela.

Baena, G (2015). Planeación prospectiva estratégica. Teorías, metodologías, y buenas prácticas en América Latina. México: Proyecto PAMIME, Universidad Nacional Autónoma de México. 
Calero, S. y Fernández, A. (2007). Un acercamiento a la construcción de escenarios como herramienta para la planificación estratégica de la Cultura Física en Cuba. Revista Digital, (114).

Chermack, T., Lynham, S., y Ruona, W. (2001). A Review of Scenario Planning Literature. Future Research Quarterly, 17(2), 7-31.

Clemade, L. Y. (2010). Análisis estructural y de estrategia de actores para la proyección de estudios prospectivos en la provincia de Villa Clara. Tesis de pregrado. Universidad Central Martha Abreu de Las Villas, Villa Clara, Cuba.

Conway, M. (2004). Scenario planning: an innovative approach to strategy development. Sidney: Australasian Association for Institutional Research.

Dueñas, J., Medina, A., Ramírez, L. X., Camacho, W., y Sobenis, J. (2019). La prospectiva estratégica como herramienta de planeación a largo plazo. Revista Magazine de las Ciencias, 4 (3), 1-18. Recuperado de: https://doi.org/10.5281/zenodo.3339463

Fernández, J. (2012). Oportunidad y conveniencia de aplicar la prospectiva al sector turismo. Estudios Turísticos, (192), 7 -33.

Gándara, G. (2015). Strategic Prospective Methodology to explore sustainable futures. Journal of Modern Accounting and Auditing, 11(11), 605 - 614.

Gavigan, J.P. y Scapolo F. (2000). La prospectiva y la visión del desarrollo regional a largo plazo. IPTS Report. (56). Consultado el 05 de octubre de 2019. Recuperado de htpp://www.jrc.es/pages/iptsreport/vol56/spanish/MET1S496.htm

Godet, M y Durance, P. (2007). Prospectiva Estratégica. Problemas y métodos. Segunda Edición. Cuaderno de Lipsor. España: Prospektiker.

Godet, M. y Durance, P. (2011). La prospectiva estratégica: para las empresas y los territorios. París: UNESCO.

González, J. [et. al]. (2019). Gerencia estratégica: herramienta para la toma de decisiones en las organizaciones. Telos, 21 (1), 242 - 267.

Hernández, Y (2020). Diseño del escenario más probable de la OSDE Viajes Cuba al año 2025. Tesis de Licenciatura. Facultad de Turismo, Universidad de La Habana, Cuba.

Hernández, M., González, Y. y Despaigne, Y. (2018). Estrategia para la preparación de la reserva de directivos de Organizaciones Superiores de Dirección Empresarial (OSDE). Revista Cubana de Administración Pública y Empresarial, II (2), 137 - 147. 
Hurtado de Mendoza, S. (2003). Criterio de selección de expertos. Su procesamiento a través del método Delphy. Universidad de Barcelona: Histodidáctica. Consultado el 15 de octubre de 2019. Recuperado de http://www.ub.edu/histodidactica.

Jorge, A., Monedero, C (2016). La prospectiva estratégica como herramienta para impulsar la gestión local hacia el desarrollo sustentable. Municipio Caroní, Estado Bolívar, Venezuela. Terra Nueva Etapa, XXXII (51), 41-68. Recuperado de: http://www.redalyc.org/articulo.oa?id=72146268003

Martín, R. (2010). Principios, Organización y Prácticas del turismo. Primera Parte. La Habana: Félix Varela.

Martínez, I. y Baeza, M. (2016). Actividad de intermediación turística: tipología y formas jurídicas organizativas en Cuba. Justicia Juris, 12(2), 21 -32.

Montoya, G y Bedoya, O. (2018). Prospectiva de sostenibilidad energética de Creaciones Arrurri Sas Grisales, Universidad Cooperativa de Colombia. Consultado el 20 de octubre de 2019. Recuperado de https://repository.ucc.edu.co/handle/20.500.12494/7688.

Perilla, R. B. y González, M.B. (2017). Escenarios de futuro como principal herramienta de la prospectiva estratégica. Gestión \& Finanzas, 1 (1), 29 - 35.

Prieto, J. (2012). Gestión Estratégica Organizacional (Cuarta Edición). Bogotá: ECOE.

Rodríguez, M., Viamonte, C., Hernández, Y., Sánchez, Y., y Velasteguí, E. (2019). La gestión de servicios de la Sucursal Ventas Internacionales de la agencia de viajes Gaviota Tours con los tour operadores alemanes Aventoura Cubareisen y TourCom. Revista electrónica Ciencia Digital, 3(1), 394-409. Consultado el 08 de octubre de 2019. Recuperado de: http://cienciadigital.org/ revistacienciadigital2/index.php/CienciaDigital larticle/view/309/721

Salas, M. (2013). Prospectiva territorial: aproximación a una base conceptual y metodológica. Caracas: Universidad de los Andes.

Tapia, G. (2016). Fundamentos de la planeación estratégica prospectiva. En: Jornadas Nacionales de Administración Financiera (XXXVI:2016). Buenos Aires: Universidad de Buenos Aires.

Thompson, A, et al. (2012). Administración estratégica: teorías y casos (18 va Edición). México: McGrawHill.

Vergara, J. C., Fontalvo, T.J y Maza, F. (2010). La planeación por escenarios: Revisión de conceptos y propuestas metodológicas. Prospect, 8 (2), 21 - 29.

Viajes Cuba S.A. (2016). Planeación Estratégica (2017-2022). La Habana. 